\title{
INCIDÊNCIA DE DANOS DE Diabrotica speciosa EM CULTIVARES E LINHAGENS DE BATATA
}

\section{LARVAL INCIDENCE AND DAMAGE OF Diabrotica speciosa ON POTATO CULTIVARS AND CLONES}

\author{
Luiz Antonio Salles ${ }^{1}$
}

\section{RESUMO}

A cultura da batata é atacada por diversas pragas subterrâneas, sendo que a principal é a vaquinha, Diabrotica speciosa (Col. Chrysomelidae). O objetivo deste trabalho foi o de estudar a incidência de larvas de D. speciosa em tubérculos de cultivares e linhagens de batata para consumo de mesa e de indústria. Foram conduzidos dois experimentos: um com a exclusão total de qualquer outra praga que não a vaquinha e outro em condições naturais de lavoura. No primeiro, as cultivares de batata foram plantadas em solo intensamente hortado e sob gaiolas teladas (confinamento). O segundo, foi desenvolvido em condições normais de plantio de batata. Os experimentos foram desenvolvidos na EMBRAPA-CPACT, em Pelotas, RS, durante a safra de primavera. Foram estudadas cultivares de mesa Baronesa, Cristal, Macaca, Monte Bonito, Trapeira e as linhagens $C$ 1485687, C-12263580, CR-1290582 e de indústria, Atlantic, Asterix, Baraka, Bintje, Catucha, Cicklamen, Panda e a linhagem C-15822590. No experimento de confinamento, não houve diferença significativa entre as cultivares para indústria. Nas cultivares Panda, Asterix e Atlantic, a média geral de furos por tubérculo foi muito maior do que nas demais cinco cultivares, sugerindo que essas três cultivares teriam maior suscetibilidade à incidência e dano de larvas de vaquinha. Nesse mesmo tipo de experimento, entre as cultivares de mesa, ocorreu diferença significativa na cultivar Baronesa e na linhagem C-12261580, sendo as duas com maiores médias de furos por tubérculo, indicando a possibilidade de serem mais suscetíveis à incidência e dano de larvas de vaquinha. As demais cultivares e linhagens constituíram um grupo em que não foi possível detectar diferenças entre si. A cultivar Baronesa foi a que teve maior número médio de furos por tubérculo. As cultivares para indústria podem ser separadas em dois grupos extremos quanto à incidência de larvas $e$ danos causados pela vaquinha em condições naturais. As cultivares que tiveram menor incidência, independentemente do tamanho do tubérculo, foram Catucha, Baraka e Atlantic. As que tiveram maior incidência foram Asterix e Bintje. Nas cultivares de mesa, a linhagem C-1485687 e a cultivar Cristal foram as que tiveram maior quantidade de tubérculos enquadrados na categoria sem furo, diferindo das demais. A linhagem C-1485687 foi a menos atacada pelas larvas de vaquinha, sugerindo a menor suscetibilidade à incidência dessa praga. Conclui-se que existem diferenças quanto à incidência de larvas de vaquinha entre as cultivares e linhagens de batata, tanto para indústria como para mesa.

Palavras-chave: vaquinha, Solanum tuberosum, resistência, seleção.

\section{SUMMARY}

Potato (Solanum tuberosum) is one of the most important staple food in Brazil, especially for the south region of the country. The southamerican rootworm, Diabrotica speciosa (Col. Chrysomelidae), is the key soil pest attacking stolons and tubers. Its control in fields is based on use of soil insecticides. Damage to potato cultivar and clone tubers by feeding larvae od D. speciosa was evaluated under cage and field conditions. This study was carried out at EMBRAPA-CPACT, in Pelotas, RS (Brazil), during the spring potato season of 1997. Eight potato cultivars and clones for fresh consumption were studied: Baronesa, Cristal, Macaca, Monte Bonito, Trapeira, clone C1485687, clone C-12263580 and clone CR-1290582, and also eight cultivars and clone for processing: Atlantic, Asterix, Baraka, Bintje, Catucha, Cicklamen, Panda and clone $C$ 15822590. All treatments (cultivars and clone) were replicated four times in a complete random block design. The effect of larval infestation was measured by number of feeding holes in the tuber. In the caged experiment, no significant differences occurred at cultivar and clone groups, either for fresh consumption or processing. However, Panda, Asterix and Atlantic, among processing cultivars and clones, were those with the highest number of southamerican rootworm larvae holes (damage). Among cultivars and clones for fresh consumption, Baronesa and clone C-11261580 had the highest average number of holes. It was concluded that larvae of $\boldsymbol{D}$. speciosa fed on any potato cultivar or clone tubers. The extent to which this occurs depend on the cultivar or clone itself, although it was not possible to indicate any determined resistance level among those potato cultivars, but only tendencies.

Key words: southamerican rootworm, Solanum tuberosum, resistance, screening.

\footnotetext{
1 Engenheiro Agrônomo. PhD., Pesquisador, Embrapa-Clima Temperado(CPACT), CP 403. 96001-970 Pelotas- RS. E-mail: Salles@cpact.embrapa.br.
} 


\section{INTRODUÇÃO}

A batata é um dos alimentos básicos da população brasileira, especialmente nas regiões do sul do Brasil. A cultura da batata ocupa $30 \%$ da área cultivada com hortaliças no país, sendo plantados ao redor 170 mil hectares, colhendo-se em torno de 2,5 milhões de toneladas anualmente (IBGE, 1996). Atualmente, a produção brasileira destina-se quase que totalmente para o consumo in natura, sendo somente $4 \%$ do consumo da batata do País através de produtos industrializados. Todavia, essa situação está se alterando rapidamente e o consumo de batata industrializada está crescendo cerca de $30 \%$ ao ano no Brasil (BUSO, 1996). No Rio Grande do Sul, por exemplo, há marcante e crescente tendência ao plantio de cultivares para a indústria.

A batata, no Rio Grande do Sul, é atacada pelas diversas pragas subterrâneas, sendo que a principal é a vaquinha, Diabrotica speciosa (Col. Chrysomelidae) (BONINE, 1997). Essa espécie predomina sobre as demais do mesmo gênero (GASSEN, 1996), sendo uma das mais importantes pragas da agricultura brasileira. Ataca mais de vinte culturas e constitui fator limitante em grande número delas, como feijão, milho, batata e diversas hortaliças, especialmente cucurbitáceas. D. speciosa é uma espécie do Novo Mundo e, atualmente, distribui-se através da América Latina. É uma espécie multivoltina e polífaga (BONINE, 1997). Nos Estados Unidos, por exemplo, espécies do gênero Diabrotica são pragas importantes do milho, mas não da batata (KRYSAN, 1986). Há exemplos de resistência a inseticidas por pragas desse gênero, como relata METCALF (1986) para a $\boldsymbol{D}$. virgifera, praga mais importante do milho na América do Norte, que é considerada um exemplo clássico de "praga feita pelo homem"; já que existem diversos casos de populações resistentes a inseticidas. Até o presente, não foi relatado caso de resistência de $\boldsymbol{D}$. speciosa à inseticida no Brasil.

O estudo de resistência de genótipos ao ataque de larvas de $\boldsymbol{D}$. speciosa foram desenvolvidos para batata (FRANÇA et al., 1993, BONINE, 1997), batata-doce (GONÇALVES, 1998) e feijão (YUKI et al., 1993, TOMASO \& BOIÇAS JUNIOR, 1997). Todos demonstraram que havia diferentes níveis de resistência ao ataque dessa praga nos genótipos estudados.

O controle de larvas de D. speciosa em batata, através de inseticidas químicos, tem sido constante e com tendência de aumento de uso, tanto em quantidade como em área, especialmente para os produtores que estejam produzindo para atender o exigente mercado atacadista e industrial. $\mathrm{O}$ uso de inseticida de solo, por exemplo, é feito de maneira generalizada e sistemática, sem considerar possíveis fatores que influenciam a incidência de pragas de solo, como o tipo de solo, época de plantio e cultivar.

O objetivo deste trabalho foi estudar a incidência relativa de larvas de $\boldsymbol{D}$. speciosa em tubérculos de cultivares e linhagens de batata destinadas ao consumo de mesa e para indústria, a fim de propiciar elementos que possam ser usados no manejo dessa praga.

\section{MATERIAL E MÉTODOS}

O estudo foi desenvolvido através de dois experimentos na EMBRAPA-CPACT, em Pelotas, RS, ambos instalados em 29/8/1997, na safra de primavera. No primeiro experimento, as cultivares e linhagens de batata foram plantadas em solo intensamente hortado e sob gaiolas teladas (confinamento), com exclusão total de qualquer outra praga que não a vaquina. $\mathrm{O}$ segundo experimento foi desenvolvido sob condições normais de plantio de batata, em solo arenoso e com boa drenagem (experimento de lavoura).

$\mathrm{O}$ experimento de confinamento foi desenvolvido em gaiolas teladas de 2,0 x 1,0 x 1,5 metros, colocadas em áreas onde o solo havia sido lavrado, duas vezes gradeado e rastilhado para a destruição e remoção de qualquer inseto no solo. As batatas foram plantadas no espaçamento de $0,30 \mathrm{x}$ 0,50 metros, havendo oito plantas em cada gaiola, cada uma com as oito cultivares e linhagens estudadas, agrupadas em cultivares e linhagens para mesa e para a indústria. $\mathrm{O}$ delineamento experimental foi blocos ao acaso, com quatro repetições (gaiola). As cultivares e linhagens foram plantadas ao acaso na gaiola.

Foram estudadas as cultivares de mesa Baronesa, Cristal, Macaca, Monte Bonito, Trapeira e as linhagens C-1485687, C-12263580, CR-1290582, e as cultivares de indústria Atlantic, Asterix, Baraka, Bintje, Catucha, Cicklamen, Panda e a linhagem C15822590.

Foram feitas três infestações com adultos de $\boldsymbol{D}$. speciosa em cada gaiola, coletados de hospedeiros da região. Os insetos foram mantidos em laboratório por cerca de 15 dias antes do confinamento nas gaiolas, alimentando-se com folhas de batata e pedaços de abóbora. Os adultos foram pegos ao acaso, sem distinção de tamanho ou sexo. Em 
cada gaiola foram colocados 100 adultos, 35 aos 40 dias; 30 aos 47 dias e 35 aos 54 dias após o plantio, visando a assegurar infestação uniforme entre as oito cultivares e linhagens, já que havia diferenças no desenvolvimento de plantas. Os insetos permaneceram nas gaiolas até a colheita do experimento.

No experimento de lavoura, o preparo do solo constou de uma lavra e duas gradagens. As parcelas foram de três filas de plantas com cinco plantas em cada fila $(0,30 \times 0,80$ metro de espaçamento), perfazendo 15 plantas de batata em cada parcela. $\mathrm{O}$ delineamento experimental foi blocos ao acaso, com quatro repetições. Durante o ciclo de desenvolvimento da batata foram usados apenas fungicidas.

$$
\text { A colheita foi realizada em }
$$

01/12/1997, aos 95 dias após o plantio, quando a maioria das cultivares já apresentavam sinais de maturação. No experimento de confinamento, foram colhidos todos os tubérculos da planta e, no de lavoura, colheram-se todos os tubérculos das cinco plantas da fila central da parcela, independente do tamanho e formato.

No experimento de confinamento, a avaliação da incidência foi feita através do número total de furos causados por larvas, em cada tubérculo. No experimento de lavoura, os tubérculos foram separados em dois tamanhos. Os que ficaram retidos em peneira de $5 \times 5 \mathrm{~cm}$ e em de $3,5 \times 3,5 \mathrm{~cm}$ de malha foram classificados em tubérculos grandes e pequenos, respectivamente. Esses tubérculos foram subclassificados nas seguintes categorias de dano: $1=$ sem furo; $2=1-3 ; 3=4-7 ; 4=8-11$ furos e $5=$ mais de 12 furos característicos de larva de vaquinha por tubérculo.

Os dados foram submetidos à análise de variância e as médias comparadas pelo teste de Duncan $(\mathrm{P}<0,05)$.

\section{RESULTADOS E DISCUSSÃO}

No experimento de confinamento, não houve diferença significativa entre as cultivares para indústria (Tabela 1). Nas cultivares Panda, Asterix e Atlantic, a média geral de furos por tubérculo, foi maior do que nas demais cinco cultivares ou linhagens, sugerindo que essas três cultivares teriam maior suscetibilidade à incidência e dano de larvas de vaquinha. Entre essas três cultivares, a média de furos por tubérculos foi praticamente igual, embora maior em Panda e Asterix. O grupo de cultivares que teve menores médias de furos por tubérculo, em
Tabela 1 - Número médio de furos causados por larvas de $\boldsymbol{D}$. speciosa por tubérculo em cultivares para indústria (I) e mesa (M). Experimento de confinamento. Pelotas, 1997.

\begin{tabular}{lclc}
\hline $\begin{array}{c}\text { Cultivar ou } \\
\text { Linhagem (I) }\end{array}$ & Número de furos & $\begin{array}{c}\text { Cultivar ou } \\
\text { Linhagem (M) }\end{array}$ & Número de furos \\
\hline Panda & $16,2 \mathrm{a}$ & Baronesa & $34,5 \mathrm{a}$ \\
Asterix & $15,3 \mathrm{a}$ & Ling.C-11263580 & $31,2 \mathrm{a}$ \\
Atlantic & $12,4 \mathrm{a}$ & Ling.C-1485687 & $9,6 \mathrm{~b}$ \\
Bintje & $6,6 \mathrm{a}$ & Ling.CR-1290582 & $9,6 \mathrm{~b}$ \\
Cicklamen & $5,5 \mathrm{a}$ & Monte Bonito & $9,0 \mathrm{~b}$ \\
Catucha & $4,9 \mathrm{a}$ & Trapeira & $8,7 \mathrm{~b}$ \\
Baraka & $4,8 \mathrm{a}$ & Cristal & $6,6 \mathrm{~b}$ \\
Linh.C-15822590 & $4,6 \mathrm{a}$ & Macaca & $6,5 \mathrm{~b}$ \\
& & & \\
\hline
\end{tabular}

Médias seguidas por letras distintas diferem em nível de 5\% de significância pelo teste de Duncan.

ordem decrescente, foi o da Bintje, Cicklamen, Catucha, Baraka e a linhagem C-15822590 (Tabela 1).

Ainda no experimento de confinamento, entre as cultivares de mesa, ocorreram diferenças significativas na cultivar Baronesa e na linhagem C12263580, sendo as duas com maiores médias de furos por tubérculo, indicando a possibilidade de serem mais suscetíveis à incidência e dano de larvas (Tabela 1). As demais cultivares e linhagens constituíram um grupo em que não foi possível detectar diferenças entre si (Tabela 1). A cultivar Baronesa foi a que teve maior número médio de furos por tubérculo, e a cultivar Macaca a que apresentou menor número médio de furos por tubérculo, correspondendo ao relatado por BONINE (1997).

No experimento de lavoura, as cultivares para indústria podem ser separadas em dois grupos extremos quanto à incidência de larvas e danos causadas pela vaquinha em condições naturais. As cultivares que tiveram menor incidência, independente do tamanho do tubérculo, foram a Catucha, Baraka e Atlantic. As que tiveram maior incidência foram a Asterix e Bintje. Em posição intermediária, situaram-se as cultivares Panda, Cicklamen, e a linhagem C-15822590 (Tabelas 2 e 3).

$\mathrm{Na}$ categoria de dano 1, tubérculos sem furo, as cultivares Catucha e Baraka tiveram as maiores médias de tubérculos aí enquadrados, já as com menores médias, nessa categoria, foram a Asterix e Bintje (Tabelas 2 e 3). Analisando-se a incidência da média de furos nos tubérculos grandes, na categoria cumulativa $1+2$ (até três furos por tubérculo), podese determinar a seguinte ordem decrescente, entre as oito cultivares, sem considerar as diferenças estatísticas ocorridas: Catucha, Baraka, Atlantic, Panda, linhagem C-15822590, Cicklamen, Bintje e Asterix 
Tabela 2 - Número médio de tubérculos grandes danificados por larvas de $\boldsymbol{D}$. speciosa por categoria de dano, em condições naturais; cultivares para indústria. Pelotas, 1997.

\section{Cultivar ou} Linhagem

\begin{tabular}{lcccccc}
\hline & & & & & & \\
& & 2 & 3 & 4 & 5 & $1+2$ \\
\cline { 2 - 7 } & & & & & & \\
Asterix & $0,5 \mathrm{bc}$ & $0,2 \mathrm{e}$ & $5,5 \mathrm{ab}$ & $4,6 \mathrm{a}$ & $6,8 \mathrm{a}$ & $0,7 \mathrm{~d}$ \\
Atlantic & $2,8 \mathrm{ab}$ & $9,5 \mathrm{ab}$ & $3,9 \mathrm{ab}$ & $2,2 \mathrm{a}$ & $0,0 \mathrm{~d}$ & $12,5 \mathrm{abc}$ \\
Baraka & $5,1 \mathrm{a}$ & $8,5 \mathrm{abc}$ & $2,5 \mathrm{~b}$ & $0,9 \mathrm{a}$ & $0,0 \mathrm{~d}$ & $13,8 \mathrm{ab}$ \\
Bintje & $0,0 \mathrm{c}$ & $2,9 \mathrm{~d}$ & $4,0 \mathrm{ab}$ & $4,7 \mathrm{a}$ & $4,3 \mathrm{ab}$ & $3,2 \mathrm{~d}$ \\
Catucha & $5,6 \mathrm{a}$ & $10,6 \mathrm{a}$ & $3,9 \mathrm{ab}$ & $2,8 \mathrm{a}$ & $0,6 \mathrm{~d}$ & $16,3 \mathrm{a}$ \\
Cicklamen & $2,8 \mathrm{ab}$ & $5,2 \mathrm{~cd}$ & $7,6 \mathrm{a}$ & $2,4 \mathrm{a}$ & $3,0 \mathrm{bc}$ & $7,4 \mathrm{c}$ \\
Panda & $2,0 \mathrm{abc}$ & $7,9 \mathrm{abc}$ & $6,2 \mathrm{a}$ & $2,2 \mathrm{a}$ & $0,0 \mathrm{~d}$ & $10,1 \mathrm{bc}$ \\
Linh.C-15822590 & $1,3 \mathrm{bc}$ & 6,1 & $5,6 \mathrm{bc}$ & $1,9 \mathrm{a}$ & $1,0 \mathrm{~cd}$ & $7,5 \mathrm{c}$ \\
& & & & & & \\
\hline & & & & & & \\
C.V \% & 24,5 & 13,7 & 16,5 & 29,8 & 22,7 & 14,3 \\
& & & & & & \\
\hline
\end{tabular}

Médias seguidas por letras distintas na coluna diferem em nível de $5 \%$ de significância pelo teste de Duncan.

* 1 =tubérculo sem furo; $2=1-3 ; 3=4-7 ; 4=8-11 ; 5=$ mais de 12 furos por tubérculo.

(Tabela 2). A mesma análise, para tubérculos pequenos, revela a seguinte ordem: Catucha, Panda, Atlantic, linhagem C-15822590, Baraka, Cicklamen, Bintje, e Asterix (Tabela 3). As maiores diferenças foram na cultivar Baraka, que em tubérculos pequenos ficou em quinto lugar, enquanto que em tubérculos grandes, em segundo, e a cultivar Panda, em tubérculos grandes, situou-se em quarto entre as oito cultivares e linhagem e ascendeu para segundo lugar em tubérculos pequenos. Entre as demais, houve correspondência, sugerindo a influência relativa do tamanho do tubérculo na incidência de larvas de vaquinha. É importante considerar que quanto menor for o tubérculo de batata, maior será o potencial dano absoluto, com conseqüente depreciação comercial da batata. Além da análise da incidência de danos nos dois tamanhos de tubérculos, não se desejou estabelecer uma causa direta entre outros possíveis fatores intrínsecos da cultivar ou linhagem (como cor e espessura da epiderme, firmeza da polpa, etc.), pois o trabalho visou, basicamente, a estabelecer a relação da incidência direta de D. speciosa na cultivar ou linhagem em si, incluindo o conjunto de fatores geneticamente dependentes. Obviamente, que se o objetivo fosse o de propiciar elementos para o manejo genético, certamente deveria ser esclarecido o(s) fator(s) determinante da diferença de incidência.

Nas cultivares de mesa, entre as de tamanho grande, a que apresentou maior quantidade de tubérculos enquadrados na categoria de dano 1 (sem furo) foi a linhagem C-1485687, diferindo estatisticamente das demais (Tabela 4). Essa mesma situação ocorreu entre os tubérculos pequenos, embora não ocorrendo diferença estatística com a cultivar Cristal. Assim, a linhagem C1485687 foi a menos atacada pelas larvas de vaquinha, sugerindo a menor suscetibilidade à incidência dessa praga.

A análise da categoria cumulativa $1+2$, tubérculos com até três furos, em tubérculos grandes, a ordem decrescente entre essas cultivares foi a seguinte: linhagem C-1485687, Cristal, Monte Bonito, linhagem C-12263580, Trapeira, Macaca, Baronesa e a linhagem CR-1290582 (Tabela 4). Em tubérculos pequenos, a ordem decrescente nessa categoria cumulativa de dano foi a seguinte: Trapeira, Cristal, linhagem C1485687, Macaca, Monte Bonito, linhagem CR1290582, Baronesa e linhagem C-12263580 (tabela 5). Não ocorreu, entre as cultivares de mesa, uma equivalência relativa quanto ao enquadramento médio dos tubérculos de tamanho grande e pequeno entre as oito cultivares. Desse modo, não foi possível estabelecer, pelo menos, dois grupos de cultivares com suscetibilidade extremas, independente do tamanho do tubérculo (Tabelas 4 e 5).

As diferenças obtidas entre as cultivares e linhagens, nos dois tipos de experimentos (confina-

Tabela 3 - Número médio de tubérculos pequenos danificados por larvas de $\boldsymbol{D}$. speciosa por categoria de dano, em condições naturais; cultivares para indústria. Pelotas, 1997.

\begin{tabular}{|c|c|c|c|c|c|c|}
\hline \multirow[t]{2}{*}{$\begin{array}{l}\text { Cultivar ou } \\
\text { Linhagem }\end{array}$} & \multicolumn{6}{|c|}{ Número médio de tubérculos por categoria de dano } \\
\hline & $1 *$ & 2 & 3 & 4 & 5 & $1+2$ \\
\hline Asterix & $1,7 \mathrm{~b}$ & $5,4 \mathrm{~b}$ & $4,8 \mathrm{ab}$ & $7,4 \mathrm{a}$ & $4,5 \mathrm{a}$ & $7,2 \mathrm{c}$ \\
\hline Atlantic & $6,2 a b$ & $10,6 \mathrm{a}$ & $6,8 \mathrm{a}$ & $0,9 \mathrm{bc}$ & $0,0 \mathrm{~b}$ & $16,9 \mathrm{ab}$ \\
\hline Baraka & $4,7 \mathrm{ab}$ & $10,6 \mathrm{a}$ & $8,3 \mathrm{a}$ & $0,5 \mathrm{c}$ & $0,0 \mathrm{~b}$ & $15,5 \mathrm{ab}$ \\
\hline Bintje & $2,5 \mathrm{~b}$ & $7,8 \mathrm{ab}$ & $8,5 \mathrm{a}$ & $2,4 \mathrm{bc}$ & $0,9 \mathrm{ab}$ & $10,5 \mathrm{bc}$ \\
\hline Catucha & $9,8 \mathrm{a}$ & $11,9 \mathrm{a}$ & $2,6 \mathrm{~b}$ & $0,6 \mathrm{c}$ & $1,9 a b$ & $21,9 \mathrm{a}$ \\
\hline Cicklamen & $2,9 \mathrm{~b}$ & $12,2 \mathrm{a}$ & $5,2 \mathrm{ab}$ & $3,2 \mathrm{~b}$ & $0,9 \mathrm{ab}$ & $15,2 \mathrm{ab}$ \\
\hline Panda & $6,5 \mathrm{ab}$ & $10,9 \mathrm{a}$ & $5,7 \mathrm{ab}$ & $0,5 \mathrm{c}$ & $0,0 \mathrm{~b}$ & $17,8 \mathrm{ab}$ \\
\hline Linh.C-15822590 & $4,0 \mathrm{ab}$ & $11,8 \mathrm{a}$ & $6,3 \mathrm{ab}$ & $2,3 \mathrm{bc}$ & $0,6 \mathrm{~b}$ & $16,3 \mathrm{ab}$ \\
\hline C.V \% & 26,9 & 11,6 & 17,1 & 23,1 & 39,7 & 13,3 \\
\hline
\end{tabular}

Médias seguidas por letras distintas na coluna diferem em nível de 5\% de significância pelo teste de Duncan.

* 1 =tubérculo sem furo; $2=1-3 ; 3=4-7 ; 4=8-11 ; 5=$ mais de 12 furos por tubérculo. 
Tabela 4 - Número médio de tubérculos grandes danificados por larvas de $\boldsymbol{D}$. speciosa por categoria de dano, em condições naturais; cultivares para mesa. Pelotas, 1997.

\begin{tabular}{lcccccc}
\hline \multicolumn{1}{c}{$\begin{array}{c}\text { Cultivar ou } \\
\text { Linhagem }\end{array}$} & \multicolumn{6}{c}{ Número médio de tubérculos por categoria de dano } \\
& \multicolumn{1}{c}{$1^{*}$} & 2 & 3 & 4 & 5 & $1+2$ \\
\cline { 2 - 7 } & & & & & & \\
& $0,6 \mathrm{~b}$ & $1,2 \mathrm{bc}$ & $2,2 \mathrm{~b}$ & $2,3 \mathrm{a}$ & $8,3 \mathrm{a}$ & $1,7 \mathrm{~cd}$ \\
Baronesa & $1,9 \mathrm{~b}$ & $9,9 \mathrm{a}$ & $3,7 \mathrm{ab}$ & $2,6 \mathrm{a}$ & $1,3 \mathrm{c}$ & $11,9 \mathrm{ab}$ \\
Cristal & $0,5 \mathrm{~b}$ & $5,5 \mathrm{a}$ & $8,4 \mathrm{a}$ & $1,7 \mathrm{a}$ & $2,4 \mathrm{bc}$ & $6,0 \mathrm{bc}$ \\
Macaca & $2,2 \mathrm{~b}$ & $8,6 \mathrm{a}$ & $4,9 \mathrm{ab}$ & $1,9 \mathrm{a}$ & $1,6 \mathrm{bc}$ & $11,1 \mathrm{ab}$ \\
M. Bonito & $0,9 \mathrm{~b}$ & $5,2 \mathrm{ab}$ & $5,2 \mathrm{ab}$ & $3,5 \mathrm{a}$ & $1,8 \mathrm{bc}$ & $6,0 \mathrm{bc}$ \\
Trapeira & $6,9 \mathrm{a}$ & $8,6 \mathrm{a}$ & $3,5 \mathrm{ab}$ & $0,2 \mathrm{~b}$ & $0,7 \mathrm{c}$ & $15,6 \mathrm{a}$ \\
Linh.C-1485687 & $1,0 \mathrm{~b}$ & $5,0 \mathrm{ab}$ & $4,4 \mathrm{ab}$ & $3,3 \mathrm{a}$ & $3,8 \mathrm{abc}$ & $6,2 \mathrm{bc}$ \\
Linh.C-12263580 & $0,0 \mathrm{~b}$ & $0,2 \mathrm{c}$ & $1,2 \mathrm{~b}$ & $3,9 \mathrm{a}$ & $5,9 \mathrm{ab}$ & $0,2 \mathrm{~d}$ \\
Linh.CR-129052 & & & & & & \\
\hline & 26,1 & 22,9 & 24,4 & 16,0 & 27,3 & 24,3 \\
C.V \% & & & & &
\end{tabular}

Médias seguidas por letras distintas na coluna diferem em nível de 5\% de significância pelo teste de Duncan.

* $1=$ tubérculo sem furo; $2=1-3 ; 3=4-7 ; 4=8-11 ; 5=$ mais de 12 furos por tubérculo.

mento e lavoura) não foram consistentes e correspondentes, o que, certamente, terá que ser equacionado se tais diferenças foram determinadas por fator(es) genético(s) da cultivar ou linhagem ou por

Tabela 5 - Número médio de tubérculos pequenos danificados por larvas de $\boldsymbol{D}$. speciosa por categoria de dano, em condições naturais; cultivares para mesa. Pelotas, 1997.

\begin{tabular}{lcccccc}
\hline \multicolumn{1}{c}{$\begin{array}{c}\text { Cultivar ou } \\
\text { Linhagem }\end{array}$} & \multicolumn{6}{c}{ Número médio de tubérculos por categoria de dano } \\
& & & & & & \\
& & 2 & 3 & 4 & 5 & $1+2$ \\
& & & & & & \\
\cline { 2 - 7 } & $3,2 \mathrm{bc}$ & $3,3 \mathrm{~d}$ & $5,2 \mathrm{ab}$ & $3,3 \mathrm{ab}$ & $7,4 \mathrm{a}$ & $6,8 \mathrm{bc}$ \\
Baronesa & $7,4 \mathrm{ab}$ & $12,8 \mathrm{ab}$ & $2,8 \mathrm{~b}$ & $0,6 \mathrm{c}$ & $0,6 \mathrm{c}$ & $20,6 \mathrm{a}$ \\
Cristal & $1,4 \mathrm{~cd}$ & $9,6 \mathrm{bc}$ & $9,2 \mathrm{a}$ & $0,9 \mathrm{c}$ & $1,4 \mathrm{c}$ & $11,2 \mathrm{~b}$ \\
Macaca & $2,0 \mathrm{~cd}$ & $6,9 \mathrm{~cd}$ & $3,9 \mathrm{~b}$ & $4,1 \mathrm{ab}$ & $2,3 \mathrm{bc}$ & $9,0 \mathrm{bc}$ \\
M. Bonito & $3,6 \mathrm{bc}$ & 17,1 & $5,8 \mathrm{ab}$ & $0,2 \mathrm{c}$ & $1,9 \mathrm{bc}$ & $20,8 \mathrm{a}$ \\
Trapeira & $10,9 \mathrm{a}$ & $11,3 \mathrm{abc}$ & $3,4 \mathrm{~b}$ & $0,2 \mathrm{c}$ & $1,3 \mathrm{c}$ & $19,1 \mathrm{a}$ \\
Linh.C-1485687 & $0,2 \mathrm{~d}$ & $3,7 \mathrm{~d}$ & $9,2 \mathrm{a}$ & $4,2 \mathrm{a}$ & $5,2 \mathrm{ab}$ & $4,0 \mathrm{c}$ \\
Linh.C-12263580 & $2,4 \mathrm{~cd}$ & $6,2 \mathrm{~cd}$ & $3,9 \mathrm{~b}$ & $1,9 \mathrm{bc}$ & $3,2 \mathrm{abc}$ & $8,9 \mathrm{bc}$ \\
Linh.CR-1290582 & & & & & & \\
\hline & 22,5 & 14,7 & 15,6 & 18,3 & 24,6 & 13,9 \\
& & & & & &
\end{tabular}

Médias seguidas por letras distintas na coluna diferem em nível de 5\% de significância pelo teste de Duncan.

* 1 =tubérculo sem furo; $2=1-3 ; 3=4-7 ; 4=8-11 ; 5=$ mais de 12 furos por tubérculo. fator(es) intrínseco(s) da metodologia experimental usada.

\section{CONCLUSÃO}

Existem diferenças quanto à incidência de larvas de vaquinha entre as cultivares de batata para indústria e mesa, sendo possível manejar esses fatores em programas de melhoramento genético e manejo de pragas, entre outros.

\section{REFERÊNCIAS BIBLIOGRÁFICAS}

BONINE, D.P. Suscetibilidade de cultivares de batata (Solanum tuberosum L.) à Diabrotica speciosa (Germ.) (Coleoptera:Chrysomelidae) e ocorrência de outras pragas subterrâneas. Pelotas, 1997, 59p. Dissertação (Mestrado em Fitossanidade) - Universidade Federal de Pelotas, 1997.

BUSO, J.A. A cultura da batata nos países do cone sul e do Mercosul. In: REUNIÃO TÉCNICA ANUAL DE PESQUISA E EXTENSÃO DA CULTURA DA BATATA NO RIO GRANDE DO SUL E SANTA CATARINA, 3, 1996, Santa Maria. Anais, ... Santa Maria : UFSM, 1996. 64p. p.1-16.

FRANÇA, F.H., CASTElO BRANCO, M., BUSO, J.A, et al. Avaliação de germoplasma avançado de batata, Solananum tuberosum, com resistência múltipla à insetos. In: CONGRESSO BRASILEIRO DE ENTOMOLOGIA, 14, 1993, Piracicaba. Resumos... Piracicaba : SEB, 1993. 807p. p.379.

GASSEN, D.N. Manejo de pragas associadas à cultura do milho. Passo Fundo : Aldeia Norte, 1996. 134p.

GONÇALVES, P.A.S. Suscetibilidade de clones de batata-doce a insetos de solo. Agropecuária Catarinense, Florianópolis, v.11, n.11. p.20-21, 1998.

INSTITUTO BRASILEIRO DE GEOGRAFIA E ESTATÍSTICA. Anuário Estatístico do Brasil. Rio de Janeiro : IBGE, 1996. 466p.

KRYSAN, J.L. Introduction: biology, distribution and identification of pest Diabrotica. In: KRYSAN, J.L., MILLER, T.A. (Eds). Methods for the study of pest Diabrotica. New York : Spring-Verlag, 1986. p.12-15.

METCALF, R.L. Forword. In: KRYSAN, J.L., MILLER, T.A (Eds). Methods for the study of pest Diabrotica. New York : Spring-Verlag, 1986. p.1-23.

TOMASO, C.A., BOIÇAS JUNIOR, A.L. Comportamento de genótipos de feijoeiro em relação ao ataque de Bemisia tabaci (Hemiptera, Aleyrodidae), Empoasca kraemeri (Hemiptera, Cicadellidae) e Diabrotica speciosa (Coleoptera, Chrisomelidae), na região de Jaboticabal, SP. In: CONGRESSO BRASILEIRO DE ENTOMOLOGIA, 16, 1997, Salvador. Resumos... Salvador : SEB/EMBRAPACNPMF, 1997. p.323.

YUKI, V.A., CARDOSO, C.L., LEITE, et al. Níveis de resistência de diferentes linhagens e cultivares de feijão a insetos crisomelídeos. In: CONGRESSO BRASILEIRO DE ENTOMOLOGIA, 14, 1993. Resumos... Piracicaba : SEB/ESALQ, 1993. p.400. 